\title{
Effect of Biomass Feedstock Composition on Biochar Properties Produced Through Hydrothermal Liquefaction
}

\author{
D. Bartlett, R. Venter, and S. Marx
}

\begin{abstract}
The effect that 6 different biomass feedstocks have on biochar was investigated. The biochar was produced through hydrothermal liquefaction at temperatures of $260^{\circ} \mathrm{C}$ and $300^{\circ} \mathrm{C}$. The effect of temperature was also investigated. It was discovered that lower temperatures produce more biochar, but higher temperatures ensure a biochar with properties better suited to be used as catalyst support. The feedstocks did cause the properties to vary and thus it was found that feedstocks with higher fractions of cellulose and lignin will yield larger surface areas, pore volumes and calorific values. The results proved that biochar can compete and eventually replace traditional heterogeneous catalyst.
\end{abstract}

Index Terms - Biochar, biomass, catalyst support, hydrothermal liquefaction.

\section{INTRODUCTION}

The world's fossil fuel resources are being depleted and with the raising concern of environmental pollution, due to the widely used fossil fuels, the focus to find an alternative renewable and sustainable source of fuel. The conversion of biomass into an energy resource, like biofuel, seems to be a promising path [1]. Biomass is the only renewable energy resource that can be transformed into solid, liquid or gaseous fuel [2]. It was estimated that in 2016, $95 \%$ of world-wide industrial products were produced with the use of catalytic processes [3]. This statistic establishes the importance of finding versatile, renewable, effective and economically feasible catalysts.

The nature of biomass makes it an ideal option as an energy resource for the production of sustainable energy. It can grow relatively quickly even if the land is not fertile, biomass is mostly not edible and is available in abundance [2].

Biomass is converted to energy sources with biochemical and thermochemical conversion processes. Thermochemical conversion processes include pyrolysis, combustion, hydrothermal liquefaction, transesterification, gasification, torrefaction and steam reforming [2], [1]. Hydrothermal liquefaction can be used on wet biomass [1]. A wet biomass contains more that $30 \%$ moisture [2]. Thus no extra energy for

Manuscript received October 20, 2018. This work was supported in part by the North-West University Potchefstroom Campus, Chemical Engineering. Faculty.

D. Bartlett is with the School for Chemical and Minerals Engineering of the North-West University Potchefstroom Campus, South Africa..

R. Venter is with the School for Chemical and Minerals Engineering of the North-West University Potchefstroom Campus, South Africa..

S. Marx is the School for Chemical and Minerals Engineering of the North-West University Potchefstroom Campus, South Africa.. drying or dewatering of the feedstock is needed [4] For the selective production of biochar, hydrothermal liquefaction seems to be the most effective process [2].

A few applications of biochar include carbon appropriation, bioenergy production, soil amelioration and waste water purification [2]. Currently biochar is mostly used for process fuel, however biochar can be activated and used as catalyst support [5]. A biochar catalyst can be used for the production of biodiesel [6], tar reforming processes, syngas methanation and for the Fischer-Tropsch synthesis of liquid hydrocarbons [7].

A good catalyst support requires a high surface area and well-developed pore structures. This will prevent sintering of active components and encourage a uniform dispersion of these active components [5]. Activated biochar's large BET surface area, graphite-like morphological structure and numerous pores makes it an ideal option for catalyst support. Oxidation can be used to separate biochar from catalysts, thus little effort is needed to recover precious metals [5]. The simplicity of separating the biochar catalyst from the metals, can lead to the re-use of the catalyst [6]. For activated biochar to be used as catalyst support, the BET, external and micro surface must be large, along with the pore volume and pore diameter [5]. The total acidity of the biochar is another important parameter for using biochar as a catalyst or catalyst support [3].

Biochar's surface morphology (pore distribution, functionality and area) is a crucial property to ensure that biochar is effectively utilized as catalysts and adsorbents. The ash content of the biochar can greatly affect its catalytic activity [7]. When biochar materials are carbonized through dehydrogenation, the biochar's physical properties will be carbon-rich and highly porous [3]. Biochar properties can be varied with biomass feedstock. It was proven that under the same process conditions, pine biochar had a surface area 50\% larger than peanut hull biochar [3]. Biochar must be activated before it can be used as catalyst support, because before activation biochar has a small number of pores, this is due to incomplete charring and tar-like materials being trapped within the pores. Activation will release trapped volatiles, generate new pores and enlarge the existing pores. It has been proven that mesoporous and microporous structures coexist in biochar and after the biochar have been activated [5].

\section{MATERIALS AND METHODS}

\section{A. Materials}

$\alpha$-cellulose, hemicellulose (xylan), starch, fat (pure sunflower seed oil), protein (soya powder), lignin, and a model mixture made up of all six previously mentioned 
components, served as the feedstocks to the hydrothermal liquefaction reactor. The model mixture consisted of $20 \%$ $\alpha$-cellulose, $10 \%$ xylan, $20 \%$ starch, $10 \%$ fat, $20 \%$ protein and $20 \%$ lignin. Distilled water was fed with the feedstocks as a 50 wt $\%$. Nitrogen gas was needed to create an anaerobic condition inside the reactor Hexane and acetone was used to extract non-polar and polar oils from the biochar along with the aqueous phase trapped in the pores of the biochar. However, before xylan was used as a feedstock, it was extracted from sugar cane bagasse. The extraction process required distilled water, $99.9 \%$ ethanol and a $10 \%$ sodium hydroxide solution. After drying, biochar was washed with distilled water and a $1 \mathrm{M}$ hydrochloric acid solution.

\section{B. Experimental Procedure}

For the xylan extraction, the two stage alkali pre-treatment process described in Singh et al. [8] was adapted. The sugar cane bagasse was washed for 2 hours with ethanol and then with water for another 2 hours. After the liquids were removed, the solids were soaked in a $10 \%$ sodium hydroxide solution. The mixture was kept at $65^{\circ} \mathrm{C}$ for 8 hours. The mixture was then autoclaved for 1 hour at $121^{\circ} \mathrm{C}$. The liqour was filtered from the solids and the solids were washed with distilled water. The solids were disposed of, whereas the liquor and wash water were mixed. The entire liquid was centrifuged at $4000 \mathrm{rpm}$ for $20 \mathrm{~min}$, to extract and dispose of the remaining solids. Glacial acetic acid was added to the liquor until the liqour's $\mathrm{pH}$ was 5 . An ice cold mixture of the $10 \%$ sodium hydroxide and ethanol was made in the relationship of $1: 1.5$ and added to the turbid solution. The xylan in the solution was allowed to precipitate out over a period of 10 hours. The mixture was centrifuged again at 4000 rpm for 20 min. the solid xylan was then collected.

For the hydrothermal liquefaction, the feedstocks were fed with water at a $50 \mathrm{wt} \%$ to the batch reactor. Each of the feedstocks were processed at $260^{\circ} \mathrm{C}$ and $300^{\circ} \mathrm{C}$. The starting pressure was $1 \mathrm{MPa}$ and the retention time was $20 \mathrm{~min}$. The reactor was purge of all free oxygen by filling it with nitrogen gas. Afterwards the product was weighed and the biochar was washed with hexane to extract non-polar oils and then the biochar was washed with acetone to extract polar oils. The biochar was then dried and weighed. The oils were extracted from the hexane and acetone by using a rotary evaporator.

The biochar was washed with $2 \mathrm{~L}$ distilled water for every $100 \mathrm{~g}$ of biochar. This was done at $60^{\circ} \mathrm{C}$ for 24 hours, using a magnetic stirrer and hotplate. The biochar was then washed with a $1 \mathrm{M}$ hydrochloric acid solution for 24 hours. $1 \mathrm{~L}$ of hydrochloric acid solution was added for every $100 \mathrm{~g}$ of biochar. The hydrochloric acid solution was removed from the biochar with distilled water. The biochar was washed until the filtrate from the biochar had the same $\mathrm{pH}$ as the distilled water. The goal of this step is to remove any salts that are present in the pores.

\section{Biochar characterization and analyses}

A mass recovery and biochar yield was calculated for all feedstocks at the different temperatures. A Scanning Electron Microscopy (SEM) analysis was done on all the biochars, as well as a FT-IR analysis and the biochars that charred. To analyze the physical properties, a Brunauer-Emmet-Teller
(BET) analysis with $\mathrm{CO}_{2}$ adsorption was done. Calorific value analysis was also done on the biochar

\section{RESULTS AND DISCUSSION}

\section{A. Mass recovery and biochar yield}

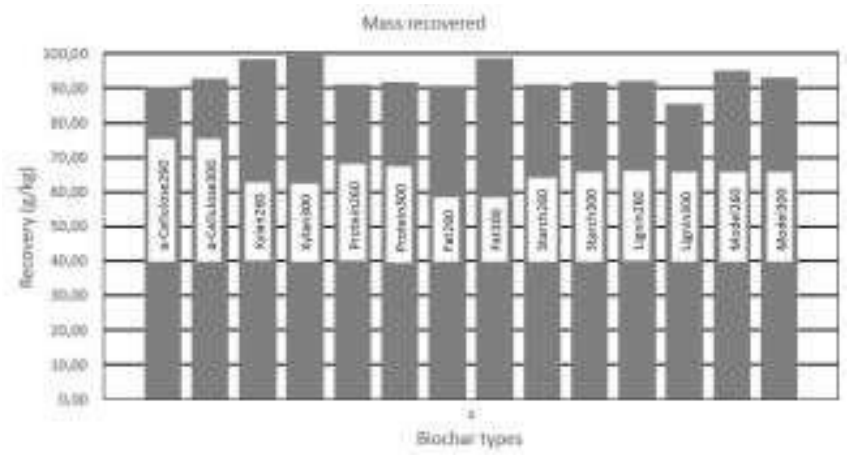

Fig. 1. Total mass recovered after hydrothermal liquefaction

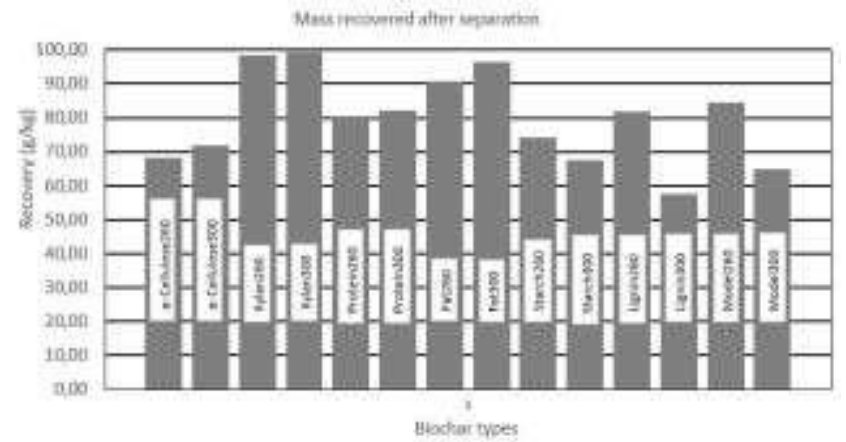

Fig. 2. Total mass recovered after separation of the solid from the liquid and volatiles

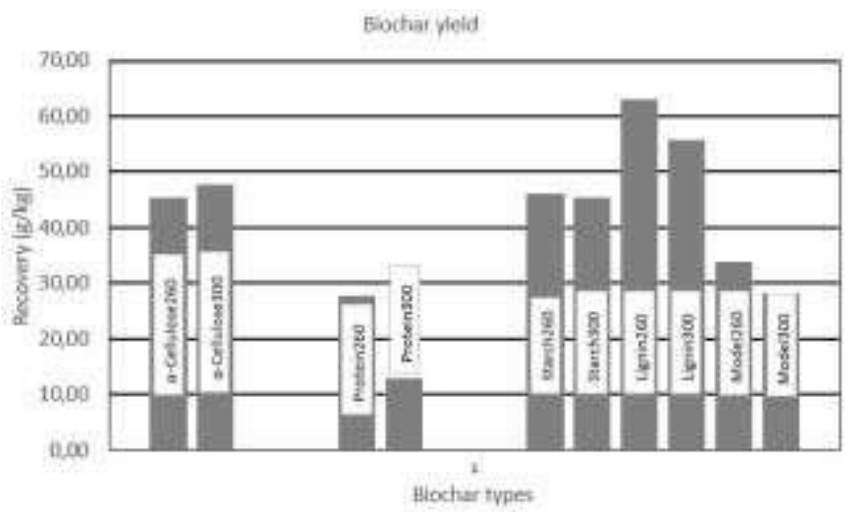

\section{Fig. 3. Biochar yields}

In Fig. 1, it can be seen that mass recovery is $90 \%$ or higher and increases with a temperature increase, except for lignin processed at $300^{\circ} \mathrm{C}$. A possible explanation for the lower mass recovery of lignin processed at $300^{\circ} \mathrm{C}$ is that more gas formed with this feedstock, than with the others. The experimental error was determined with the $\alpha$-cellulose processed at $300^{\circ} \mathrm{C}$. For the total mass recovery after hydrothermal liquefaction, the experimental error is $3.98 \%$ at a confidence level of $95 \%$.

Fig. 2, shows an overall decrease in mass recovery after separations, this is contributed to volatiles and moisture that evaporates when the biochar is dried. The argument for this statement can be further strengthened by comparing the mass 
of the wet char with the dried char. A difference of approximately $20 \mathrm{~g}$ occurred. The xylan and fat did not produce any biochar, thus a small to no decrease in mass recovery occurred. The experimental error for mass recovery after separation is $25.55 \%$ for a confidence level of $95 \%$. An error this large can be attributed to small inconsistencies in the experimental technique, e.g. the volume of hexane used to extract non-polar oils for each experiment wasn't a constant volume.

Fig. 3, shows that the biochar yield decreases as temperature increases, this is due to the increase bio-oil yield. Kambo and Dutta [2], states that with an increase in temperature, the conversion of biomass to bio-oil is more favorable than the conversion to biochar. However, the $\alpha$-cellulose biochar yield seems to increase with temperature, this is because cellulose decomposes easily between $315^{\circ} \mathrm{C}$ and $400^{\circ} \mathrm{C}$ [9], thus $\alpha$-cellulose biochar yield will increase as the temperature increases. The experimental error for the biochar yield is $8.55 \%$ at a confidence level of $95 \%$.

\section{B. SEM Analysis}

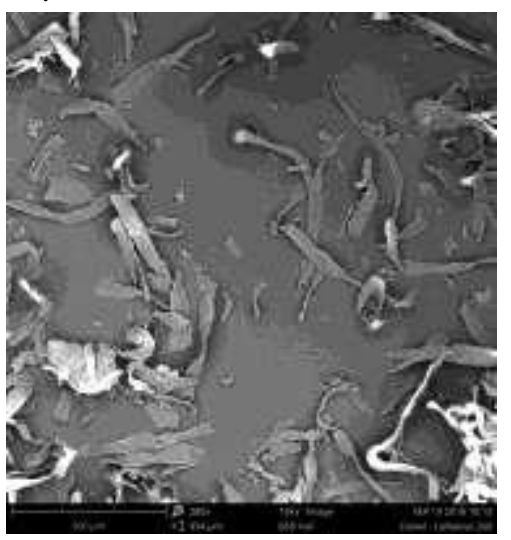

Fig. 4. $\alpha$-cellulose biochar at $260^{\circ} \mathrm{C}$

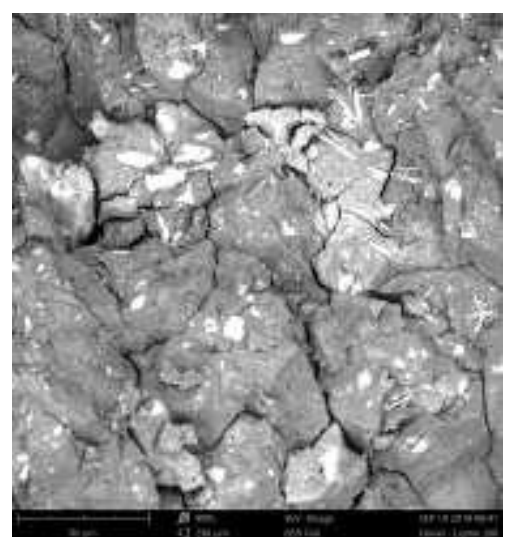

Fig. 5. Lignin biochar at $260^{\circ} \mathrm{C}$

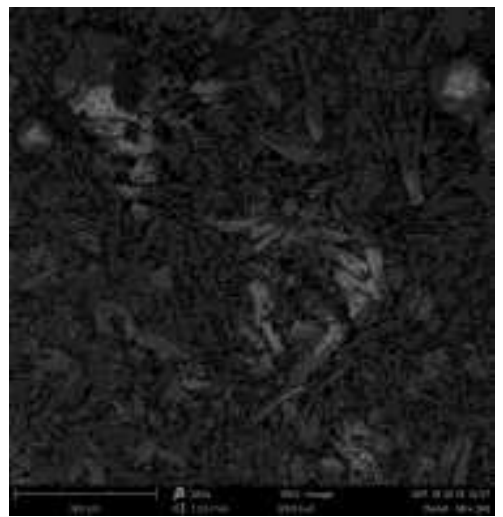

Fig. 6. Mixture biochar at $260^{\circ} \mathrm{C}$

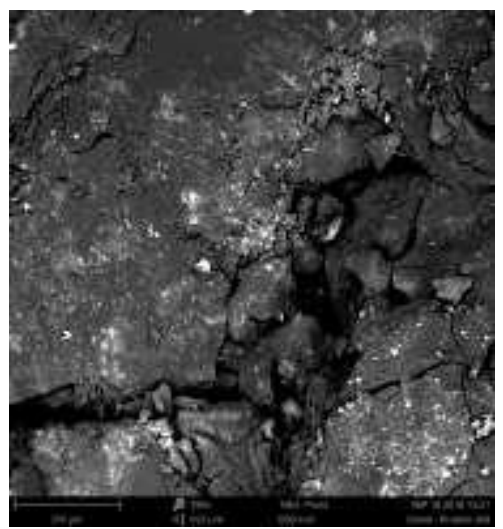

Fig. 7. Protein biochar at $260^{\circ} \mathrm{C}$

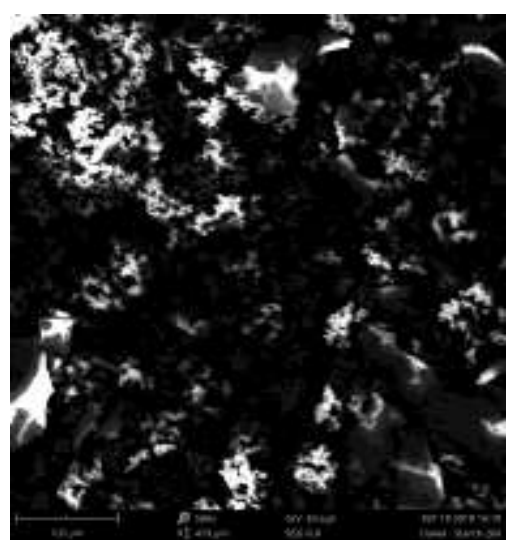

Fig. 8. Starch biochar at $260^{\circ} \mathrm{C}$

Fig.4. to Fig. 8 represent the SEM photos of all the biochars that were produced at $260^{\circ} \mathrm{C}$. The presence of the fibers and cracks in these figures imply that the charring is either incomplete or that the biomass has not started to char. When Fig. 4 is considered, it can be linked to the biochar yield of $\alpha$-cellulose and that $\alpha$-cellulose will not completely decompose or char at such a low temperature [9]. Since these biochars have not charred yet, they weren't subjected to BET analyses. 


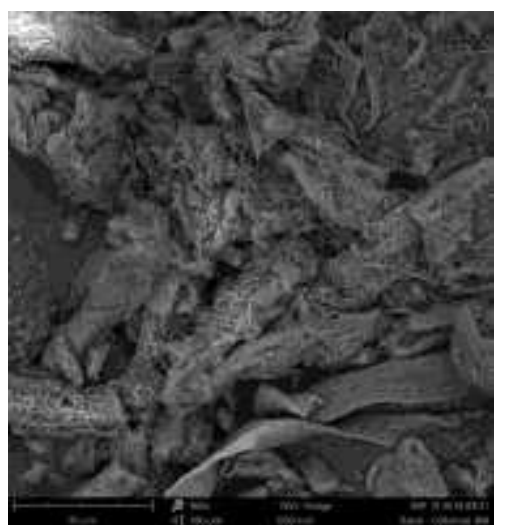

Fig. 9. $\alpha$-Cellulose biochar at $300^{\circ} \mathrm{C}$

The difference between Fig. 4 and Fig. 9is significant. The charred fibers are easily visible in Fig. 9, however there are still some uncharred fibers and even the charred fibers still maintain some of the original fiber structure and shape. This implies that biochar has formed at $300^{\circ} \mathrm{C}$, but the charring is incomplete. Again this reinforces the idea that $\alpha$-cellulose should be subjected to a higher temperature when biochar production is the goal.

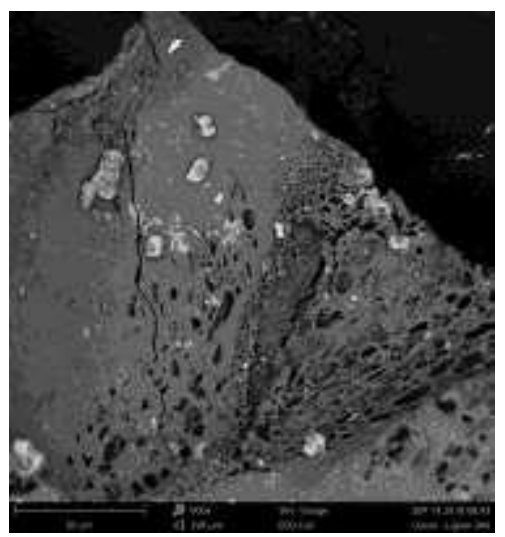

Fig. 10. Lignin biochar at $300^{\circ} \mathrm{C}$

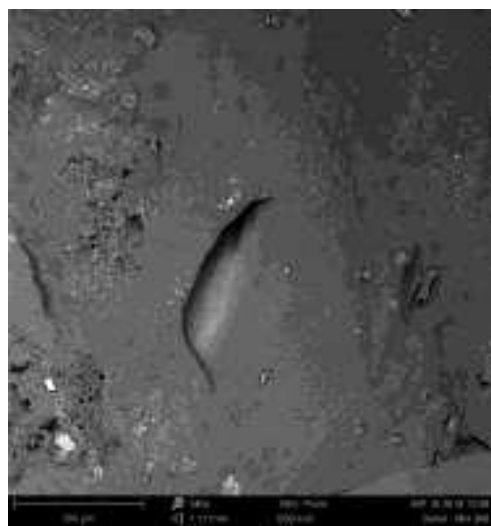

Fig. 11. Mixture biochar at $300^{\circ} \mathrm{C}$

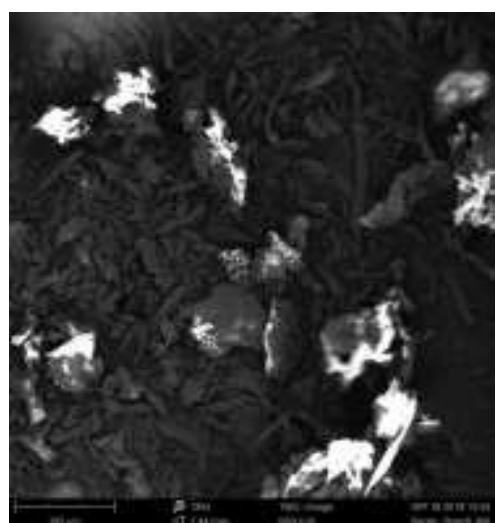

Fig. 12. Starch biochar at $300^{\circ} \mathrm{C}$

In Fig. 10, the irregular and random pores of the lignin biochar can be seen. The existing pores are as big as $8 \mu \mathrm{m}$. fibers can still be seen in the starch biochar, Fig. 12, which also implies that charring was incomplete.

All SEM photos were taken before the biochar was washed with water and hydrochloric acid.

The biochar of protein at $300^{\circ} \mathrm{C}$, was a sticky tar-like substance that could not be analyzed with the SEM or with the BET analysis.

\section{Calorific values}

As seen in Table I, for $\alpha$-cellulose, starch and lignin the higher heating values (HHV) for biochar produced at a temperature of $300^{\circ} \mathrm{C}$ increased significantly with all values being above $30 \mathrm{MJ} / \mathrm{kg}$. $\alpha$-cellulose experienced an increase of $36.42 \%$, starch experienced an increase of $73 \%$ and lignin experienced an increase of $72.91 \%$. The protein however experienced an in increase in HHV when the biochar was produced at $260^{\circ} \mathrm{C}$. the increase was a very low $6 \%$. The HHV of the mixture's biochar at both temperatures were low in comparison with the other biochars.

\section{Table I: Higher heating values (MJ/kg)}

\begin{tabular}{llll}
\cline { 2 - 3 } Biomass & Feedstock & $260^{\circ} \mathrm{C}$ & $300^{\circ} \mathrm{C}$ \\
\hline$\alpha$-cellulose & 27.79 & 23.42 & 37.91 \\
Protein & 29.01 & 30.79 & 11.71 \\
Starch & 19.94 & 21.48 & 34.54 \\
Lignin & 18.38 & 21.60 & 34.54 \\
Mixture & & 23.46 & 22.41
\end{tabular}

The higher heating values of the biochar is an indication of a higher carbon content after liquefaction. Important factors to be considered for biochar to be used as a catalyst support, is a stable structure with a consistent pore size and pore distribution and specifically for hydrotreating catalyst a high microporosity. 


\section{FT-IR analysis}

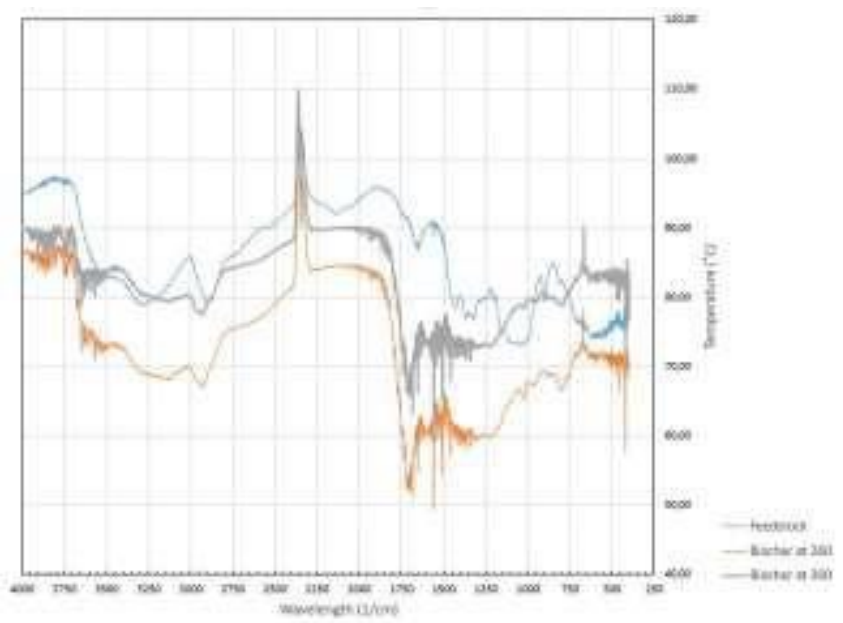

Fig. 13. FT-IR spectrum of $\alpha$-cellulose

In Fig. 13, it can be seen that the peak between 3000 and 3500 becomes less prominent with hydrothermal liquefaction. These peaks represent the $\mathrm{O}-\mathrm{H}$ and $\mathrm{CH}$ - stretch vibrations of the cellulose. The next peak between 2800 and 3000 also becomes less prominent, which is an indication of the breakdown of the cellulose to char. The peak at roughly 1700 represents, carboxylic acid, $\mathrm{C}=\mathrm{O}$ groups, this shows the increased conversion of $\mathrm{CO}$. The peak at 1550 is the arenes group, of $\mathrm{C}=\mathrm{C}$ bonds. This peak becomes more prominent which is the increase in carbon content for the biochar after liquefaction. The peaks between 750 and 1000 is the $\alpha$-cellulose that is broken down into $\beta$-glucose [10].

In Fig. 14, it can be seen that the peak between 3000 and 3500 represents the $\mathrm{O}-\mathrm{H}$ and $\mathrm{C}-\mathrm{H}$ stretch vibrations of the hemicellulose present in the lignin. The next peak between 3000 and 2750 is the aromatic ring of lignin which is decomposed. The peak at 1900 represent asymmetric $\mathrm{C}=\mathrm{C}$ bonds. The peaks between 1750 and 1000 is representative of cellulose, hemicellulose and lignin, which becomes less prominent as the lignin is decomposed. The 1100 peak represents $\mathrm{C}-\mathrm{C}-\mathrm{C}$ bindings. $\mathrm{C}-\mathrm{H}$ bonds are present at the 800 peak. The peak at 650 is the $\mathrm{O}-\mathrm{H}$ bonds of phenol groups [10].

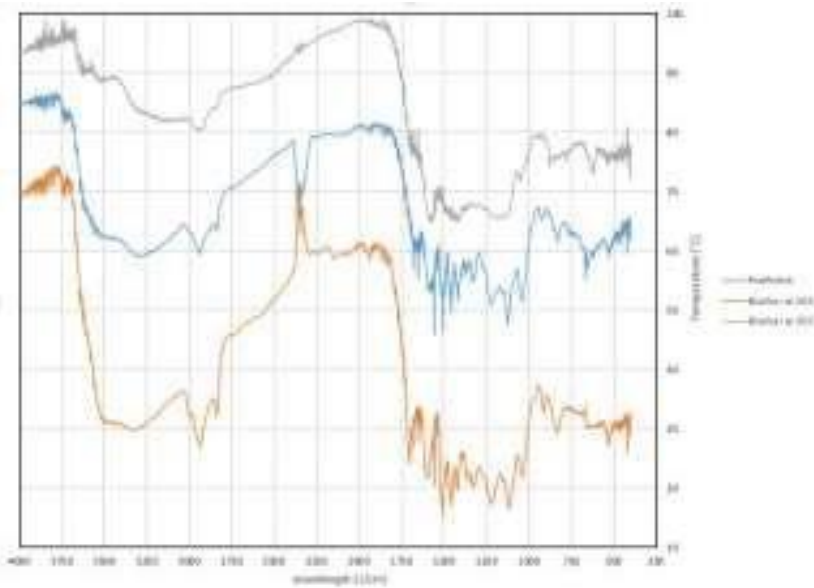

Fig. 14. FT-IR spectrum of lignin

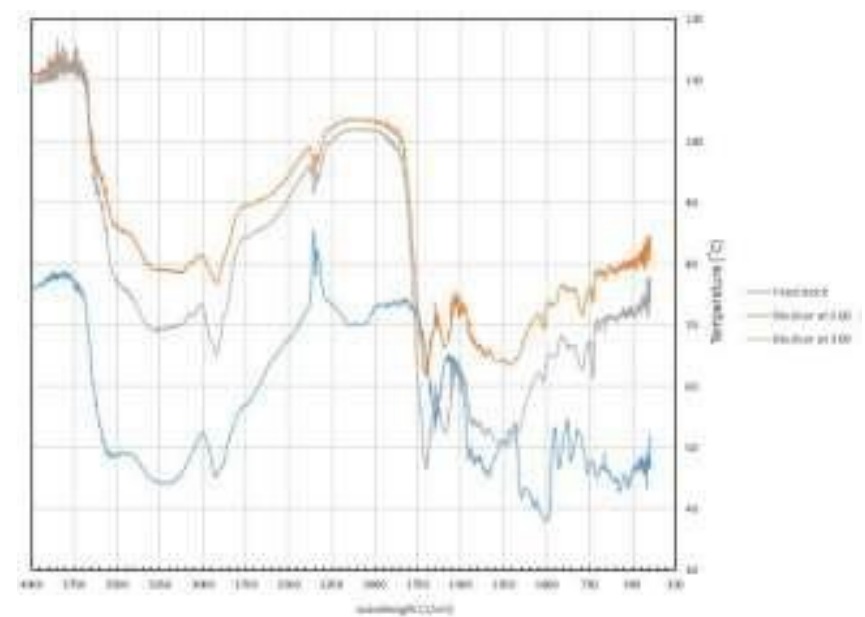

Fig. 15. FT-IR spectrum of starch

In Fig. 15, it can be seen that the peak between 3000 and 3500 represents $\mathrm{O}-\mathrm{H}$ (phenols) which decompose after liquefaction. The next peak at 2900 is the alkanes, like $\mathrm{CH}_{3}$, $\mathrm{CH}_{2}$ and $\mathrm{CH}$. The peak at 1900 represent asymmetric $\mathrm{C}=\mathrm{C}$ bonds. The peaks between 2500 and 2250 is representative of a phospine, $\mathrm{P}-\mathrm{H}$, function. The peaks between 1750-1000 represents $\mathrm{C}=\mathrm{O}, \mathrm{C}-\mathrm{O}-\mathrm{H}$ and $\mathrm{C}-\mathrm{O}$ bonds, which are carboxylic acids and arenes [10].

In Fig. 16, it can be seen that there is a prominent peak between 3000 and 3500, which represents O-H (phenols) groups. The peaks between 3000 and 2750 represent the functional groups of aldehydes and alkanes The next peak at 2900 is the alkanes functional groups, like $\mathrm{CH}_{3}, \mathrm{CH}_{2}$ and $\mathrm{CH}$. The peaks between 2500 and 2250 is representative of a phospine, P-H, function. The peaks between 1750-1000 represents carboxylic acids and amines [10].

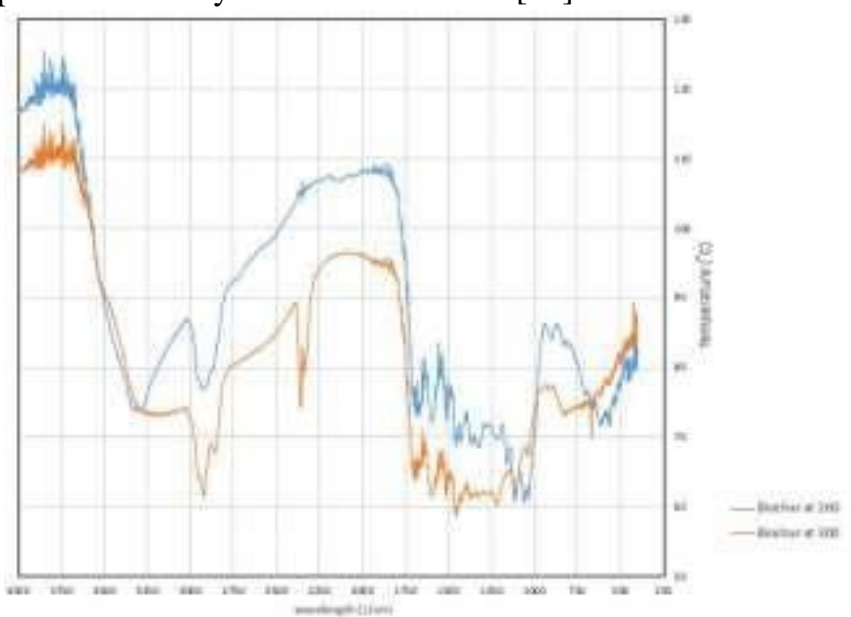

Fig. 16. FT-IR spectrum of the mixture's biochar

\section{E. BET analysis}

Table II: BET analysis of biochars produced at $300^{\circ} \mathrm{C}$

\begin{tabular}{llll}
\hline Biomass & $\begin{array}{l}\text { BET surface } \\
\text { area }\left(\mathrm{m}^{2} / \mathrm{g}\right)\end{array}$ & Pore size $(\AA)$ & $\begin{array}{l}\text { Pore } \\
\text { volume } \\
\left(\mathrm{cm}^{3} / \mathrm{g}\right)\end{array}$ \\
\hline Lignin & 133.78 & 14.17 & 0.05 \\
Starch & 120.48 & 14.2 & 0.04 \\
Mixture & 39.02 & 9.23 & 0.01 \\
$\alpha$-Cellulose & 144.24 & 14.05 & 0.05 \\
\hline
\end{tabular}

Comparing these results with the biochar and activated 
carbon used in Zhu et al. [5]. The BET surface area of all the biochars, except the mixture is larger than the biochar used in Zhu et al. [5]. The pore volume is $0.01 \mathrm{~cm}^{3} / \mathrm{g}$ smaller for lignin and $\alpha$-cellulose, while the pore sizes are larger than the biochar and activated carbon form Zhu et al. [5]. The adsorption -desorption studies were performed using $\mathrm{CO} 2$, measuring the micro-pore properties of the biochar. For lignin, starch and cellulose, the BET surface area of the micro pores are already high even before the activation of such biochars, which shows promise from a catalyst support point of view. In the case of the mixture where a significant amount of protein was included, the surface area decreased significantly compare to the cellulose, starch and lignin.

\section{CONCLUSION}

The BET, FT-IR and SEM analyses proved that biomass feedstock composition can affect the physical and chemical properties of the biochar that is produced through hydrothermal liquefaction. Biochar can be used as catalyst support and from the results it was shown that lignin and $\alpha$-cellulose are definite possibilities. This is due to the relatively high surface area and high micro-porosity, that will selectively allow specific molecules to enter the pores to get in contact with active sites created by the loading of active species into the micro-pores structure of the carbon support.

. The biochar yields and SEM analysis showed that for the production of biochar that has been fully charred, the reaction temperature must be above $300^{\circ} \mathrm{C}$. The mass yield of biochar will decrease, but the biochar's properties will be enhanced.

\section{ACKNOWLEDGMENT}

R. Venter for guidance and advice. S. Marx for assistance in helping with the FT-IR interpretation. G. Okolo for the BET analysis.

\section{REFERENCES}

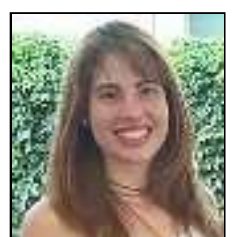

D. Bartlett was born in Vereeniging, South Africa. She graduated from Vereeniging Gimnasium in 2013 and is currently studying B.Eng in chemical engineering at the North-West University, Potchefstroom campus. 